Check for updates

Cite this: RSC Adv., 2020, 10, 14299

Received 12th February 2020

Accepted 18th March 2020

DOI: 10.1039/dOra01370f

rsc.li/rsc-advances

\title{
Synthesis of novel carbohydrate based pyridinium ionic liquids and cytotoxicity of ionic liquids for mammalian cells $\uparrow$
}

\author{
Melanie Reiß, ${ }^{a}$ Andreas Brietzke, ${ }^{b}$ Thomas Eickner, ${ }^{b}$ Florian Stein, ${ }^{a}$ \\ Alexander Villinger, (D) a Christian Vogel, ${ }^{a}$ Udo Kragl (iD a and Stefan Jopp iD *a
}

\begin{abstract}
The large pool of naturally occurring carbohydrates with their diversity in chirality and structure led to the idea of a systematic investigation of carbohydrate based ILS. To this end, we investigated the influence of different ether groups, mainly methyl or ethyl ether, on the secondary $\mathrm{OH}$ groups as well as different configurations on physical properties such as melting point, thermostability and especially the influence on cell toxicity. For this investigation we chose $\alpha$ - and $\beta$-methyl-, $\beta$-allyl- and $\beta$-phenyl $D$-glucopyranose as well as four 1-deoxy-pentoses. In order to be able to classify the results, more ionic liquids with different structural motives were examined for cytotoxicity. Here, we present data that confirm the biocompatibility of such ILs consisting of naturally occurring molecules or their derivatives. The synthesized carbohydrate based ILs were tested for their suitability as additives in coatings for medical applications such as drug-eluting balloons.
\end{abstract}

\section{Introduction}

In recent years, ionic liquids have aroused the interest of scientists in the medical research field due to their wide variety of structures and potential applications. ${ }^{1}$ Current areas of investigation include IL based drugs (Active Pharmaceutical Ingredients-Ionic Liquids) ${ }^{2}$ as well as other applications of ILs in the pharmacological field such as drug delivery systems. ${ }^{1,3}$ In such systems, the IL serves as a solvent or solvent promoter for sparingly water-soluble drugs and can thus enhance pharmacokinetic and pharmacodynamic properties considerably.

Another interesting medical application are drug-eluting balloons, which are typically used in re-stenotic lesions. ${ }^{4}$ Previous works of our group have shown that the ionic liquid cetylpyridinium salicate [CetPyr][Sal] is a potential candidate for such an application. ${ }^{5}$ This IL however, while showing good properties in drug release and homogenous coating ability, is not suited for an actual application due to cytotoxicity.

Thus we decided to further look into ILs based on natural products like amino acids ${ }^{6}$ and carbohydrates ${ }^{7}$ Especially carbohydrate based ionic liquids have piqued our interest as

${ }^{a}$ Institute of Chemistry, University of Rostock, Albert-Einstein-Straße 3a, 18059 Rostock, Germany. E-mail: stefan.jopp@uni-rostock.de

${ }^{b}$ Institute of Biomedical Engineering, University of Rostock, Friedrich-Barnewitz-Straße 4, 18119 Rostock, Germany

$\dagger$ Electronic supplementary information (ESI) available: Including experimental data for all products as well as ${ }^{1} \mathrm{H},{ }^{13} \mathrm{C}$ and ${ }^{19} \mathrm{~F}$ NMR spectra for key intermediates and all final ionic products. CCDC 19141431916778 1916780. For ESI and crystallographic data in CIF or other electronic format see DOI: 10.1039/d0ra01370f potential ILs with low cytotoxicity. While there have been a few previous studies on carbohydrate based $\mathrm{ILs},{ }^{7-10}$ most of them focused on the synthesis. Examples of previous ILs based on carbohydrates are shown in Fig. 1 .

While the use of some of these carbohydrate based ILs as solvents or for asymmetric induction ${ }^{9}$ has been studied, a study for potential medical application has yet to be done.

\section{Results and discussion}

\section{Synthesis}

The first part of our strategy was the synthesis of four new ionic liquids derived from pentoses. We chose the peracetylated species of D-ribose 1a, D-lyxose 2a, D-xylose 3a and L-arabinose 4a as starting materials, which were prepared by procedures known from literature. ${ }^{11}$ Fig. 2 shows the general synthetic pathway exemplary for D-ribose.

Starting from the peracetylated D-ribose 1a we investigated a direct reduction of the anomeric center using TMSOTf and $\mathrm{Et}_{3} \mathrm{SiH}^{12}{ }^{12}$ While this strategy successfully led to the 1-deoxy-

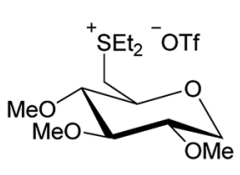

Poletti et al. ${ }^{8}$

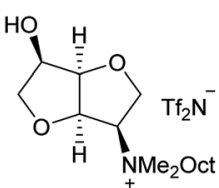

Vo-Thanh et al. ${ }^{9}$

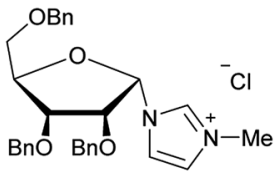

Singh et al. ${ }^{10}$
Fig. 1 Examples of carbohydrate based ILs from the literature. 
<smiles>CC(=O)OCC1OC(OC(C)=O)C(OC(C)=O)[C@H](O)[C@@H]1OC(C)=O</smiles>

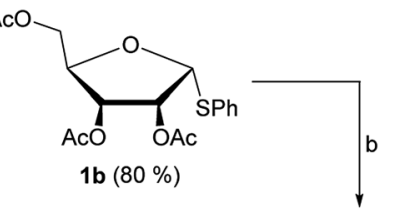

TrO
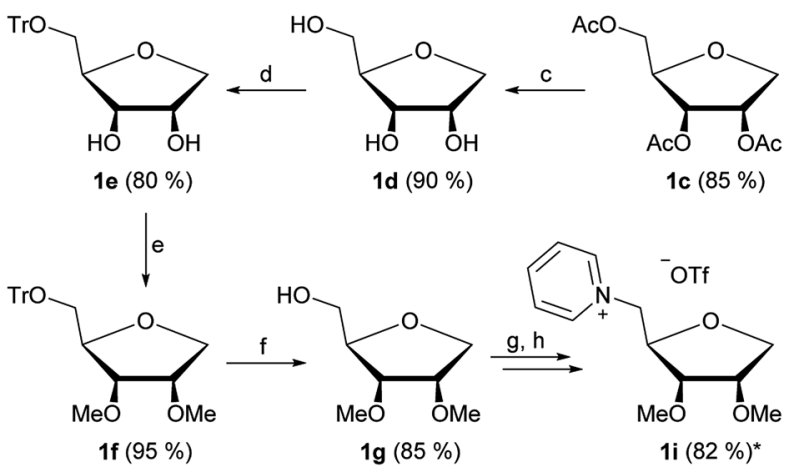

Fig. 2 Synthesis of 1-deoxy-ribose based ionic liquid $1 \mathrm{i}$; the same synthetic strategy was applied for lyxose $(2 a-i)$, xylose $(3 a-i)$ and arabinose (4a-i). (a) Thiophenol, $\mathrm{BF}_{3} \cdot \mathrm{OEt}_{2}, \mathrm{DCM}, 0{ }^{\circ} \mathrm{C} \geq$ r.t., 2 h; (b) $\mathrm{Bu}_{3} \mathrm{SnH}$, AlBN, toluene, reflux, $2.5 \mathrm{~h}$; (c) $\mathrm{MeOH}, \mathrm{Na}$, r.t., 4 h; (d) trityl chloride, NEt 3 , DMAP, DCM, r.t., overnight; (e) $\mathrm{NaH}, \mathrm{Mel}, \mathrm{DMF}, 0^{\circ} \mathrm{C} \geq$ r.t., overnight; (f) $\mathrm{AcOH}(70 \%), 70{ }^{\circ} \mathrm{C}, 45 \mathrm{~min}$; (g) $\mathrm{Tf}_{2} \mathrm{O}$, pyridine, $\mathrm{DCM}$, $0{ }^{\circ} \mathrm{C}, 10 \mathrm{~min}$; (h) pyridine, reaction at rotary evaporator, $700 \mathrm{mbar}$, $40{ }^{\circ} \mathrm{C}$; *yield over two steps.

ribose derivative 1c in a high yield of $92 \%$, it could not be applied for the other three starting materials $\mathbf{2 - 4 a}$. The yields were low and the products impure. Thus we switched to a twostep strategy of first introducing a thiophenyl group at the anomeric center followed by reduction with tributyltin hydride (Fig. 2a and b). This strategy could be applied for all four products in yields from 50 to $85 \%$.

The next four steps were the deprotection of the acetyl groups, 5-O-tritylation, introduction of the methyl ether groups on the secondary $\mathrm{OH}$ groups and lastly deprotection of the 5-O-trityl group, leading to the products $\mathbf{1 - 4 g}$ (Fig. 2c-f). These steps were generally performed with high yields ranging from 80 to $95 \%$.

Our strategy was finalized by converting the unprotected 5-OH group into a triflate, directly followed by the quarternization reaction with pyridine, yielding the products $\mathbf{1 - 4 i}$ in overall high yields after an 8-step synthesis (Fig. $2 \mathrm{~g}$ and $\mathrm{h}$ ).

By using $1 \mathrm{~d}$ and $1 \mathrm{e}$ as starting materials in a similar pathway as shown in Fig. 1 we were furthermore able to produce four additional 1-deoxy-ribose based ILs with varying groups in positions 2 and 3 .

The isopropylidene protection of 1d (Fig. 3a) allows the production of ionic liquid $\mathbf{1 k}$, which has free $\mathrm{OH}$ groups in the positions 2 and 3. Due to the instability of the isopropylidene group under acidic conditions, the synthesis of an isopropylidene protected 1-deoxy-ribose based IL was not possible at first. Said group was partly cleaved during the introduction of the 5-O-triflate group, thus a full cleavage of the isopropylidene group was performed after quarternization (Fig. $3 \mathrm{~b}-\mathrm{d}$ ). We were however able to produce the isopropylidene protected 1-deoxyribose based IL $1 \mathbf{x}$ by using mesylate instead of triflate (Fig. 4).
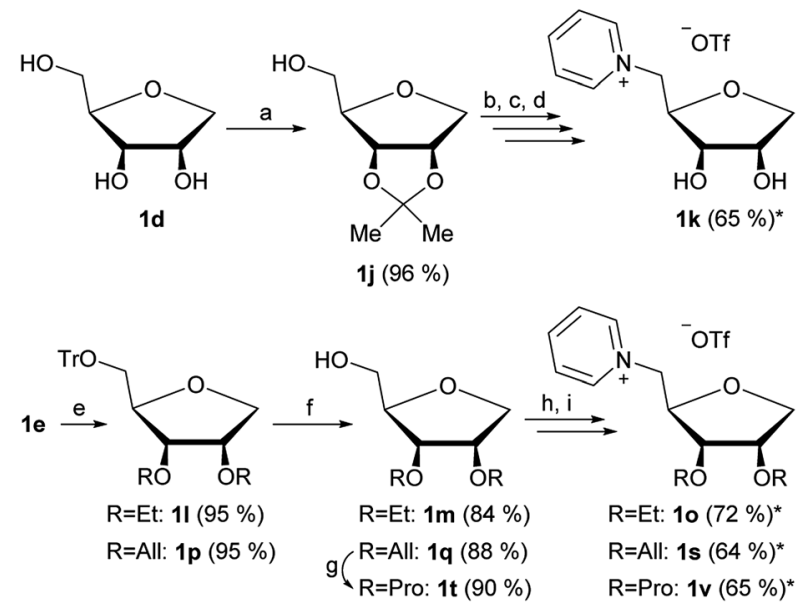

Fig. 3 Synthesis of alternative 1-deoxy-ribose ILs with varying 2- and 3-O-groups. (a) 2,2-Dimethoxy propane, camphorsulfonic acid, acetone, r.t., $1.5 \mathrm{~h}$; (b) $\mathrm{Tf}_{2} \mathrm{O}$, pyridine, $\mathrm{DCM}, 0{ }^{\circ} \mathrm{C}, 10 \mathrm{~min}$; (c) pyridine, reaction at rotary evaporator, $700 \mathrm{mbar}, 40^{\circ} \mathrm{C}$; (d) $\mathrm{AcOH}(70 \%)$, r.t., 20 min; (e) $\mathrm{NaH}$, ethyl or allyl bromide, DMF, $0{ }^{\circ} \mathrm{C} \geq$ r.t., overnight; (f) $\mathrm{AcOH}(70 \%), 70{ }^{\circ} \mathrm{C}, 45 \mathrm{~min}$; (g) $\mathrm{Pd}(\mathrm{OH})_{2}, \mathrm{MeOH}, \mathrm{H}_{2}$-atmosphere, r.t., $12 \mathrm{~h}$; (h) $\mathrm{Tf}_{2} \mathrm{O}$, pyridine, $\mathrm{DCM}, 0{ }^{\circ} \mathrm{C}, 10 \mathrm{~min}$; (i) pyridine, reaction at rotary evaporator, $700 \mathrm{mbar}, 40^{\circ} \mathrm{C}$; *yield over two steps.

By changing the reagent used for the introduction of the ether groups starting from 1e, ethyl and allyl ethers $\mathbf{1 l}$ and $\mathbf{1 p}$ have also been synthesized successfully (Fig. 3e). By further reducing the allyl group to a propyl group and carrying on with the already established strategy of introduction of the triflate followed by quarternization with pyridine, products 1o, 1s and 1v were achieved.

All nine new pyridine salts derived from pentoses are shown in Fig. 5. These ionic structures all classify as ionic liquids, as further shown under "Thermal analysis".

Our second synthetic goal was to apply the established strategy for 1-deoxy-pentoses on different glucosides. Our starting materials were $\beta$-D-methyl, allyl and phenyl glucosides 5-7a as well as $\alpha$-D-methyl glucoside 8a. Fig. 6 shows the general synthetic pathway exemplary for the $\beta$-D-methyl glucoside $\mathbf{5 a}$.

The 5-step reaction starts with the introduction of the 6-Otrityl group (Fig. 6a). This step was performed with yields from $66 \%$ when using the $\beta$-D-allyl glucoside up to $87 \%$ for the $\beta$-Dmethyl glucoside. The follow-up reactions are, similar to the synthesis shown in Fig. 2, the introduction of the methyl ether groups and afterwards the 6-O-trityl deprotection. These two

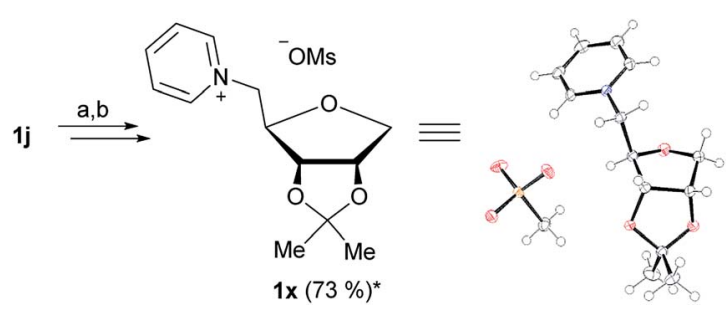

Fig. 4 Synthesis and ORTEP ${ }^{13}$ of $1 x$. (a) Mesyl chloride, pyridine, r.t., $12 \mathrm{~h}$; (b) pyridine, $125^{\circ} \mathrm{C}, 5 \mathrm{~h}$; *yield over two steps. 


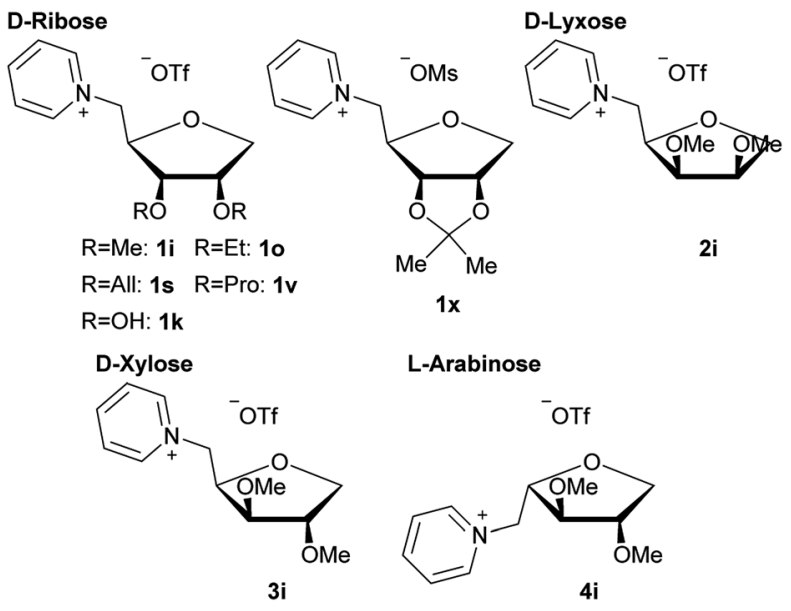

Fig. 5 Overview of 1-deoxy-pentose based ILs.

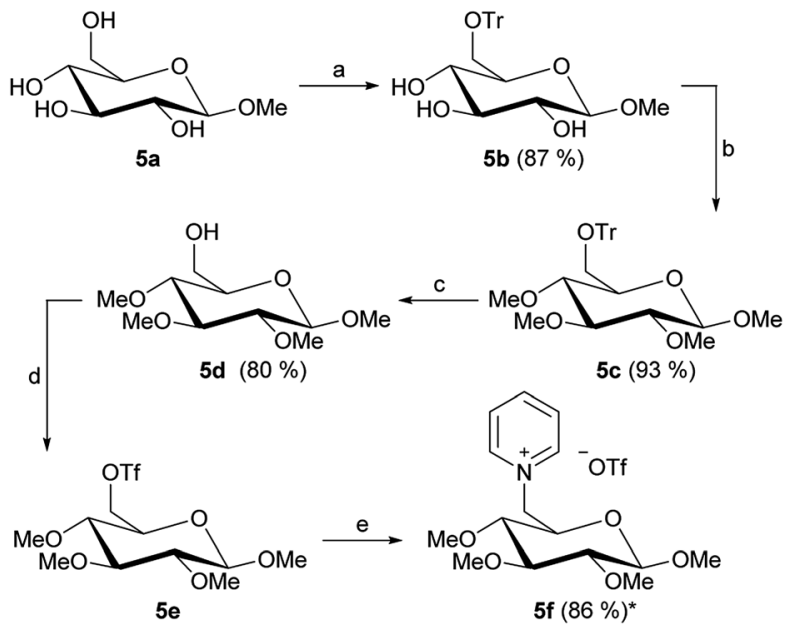

Fig. 6 Synthesis of ionic liquid 5 from $\beta$-D-methyl glucoside $5 a$; the same strategy was applied for $\beta$-allyl glucoside (6a-f), $\beta$-phenyl glucoside $(7 a-f)$ and $\alpha$-methyl glucoside $(8 a-f)$. (a) Trityl chloride, $\mathrm{NEt}_{3}, \mathrm{DMAP}, \mathrm{DCM}$, r.t., overnight; (b) $\mathrm{NaH}, \mathrm{Mel}, \mathrm{DMF}, 0{ }^{\circ} \mathrm{C} \geq$ r.t., overnight; (c) $\mathrm{AcOH}(70 \%), 70^{\circ} \mathrm{C}, 45 \mathrm{~min}$; (d) $\mathrm{Tf}_{2} \mathrm{O}$, pyridine, $\mathrm{DCM}, 0{ }^{\circ} \mathrm{C}$, $10 \mathrm{~min}$; (e) pyridine, reaction at rotary evaporator, $700 \mathrm{mbar}, 40^{\circ} \mathrm{C}$; *yield over two steps.

steps were generally performed in high yields up to $94 \%$ (Fig. $6 \mathrm{~b}$ and c). The resulting free 6-OH group of the products 5-8d was then converted into a triflate group followed by quarternization with pyridine, leading to the carbohydrate-based pyridinium triflate salts 5-8f (Fig. 6d and e).

By following the same idea as applied before for the 1-deoxypentoses, the methyl ether groups were also changed to ethyl ether groups on the $\beta$-D-methyl glucoside structure. This leads to product 5j (Fig. 7). Lastly, two further salts were derived from 5d by changing the leaving group to mesylate or tosylate, leading to $\mathbf{5 l}$ and $\mathbf{5 n}$, respectively (Fig. 7).

All seven new pyridine salts derived from glucosides are shown in Fig. 7. Most of these new products classify as ionic liquids, as further shown under "Thermal analysis".
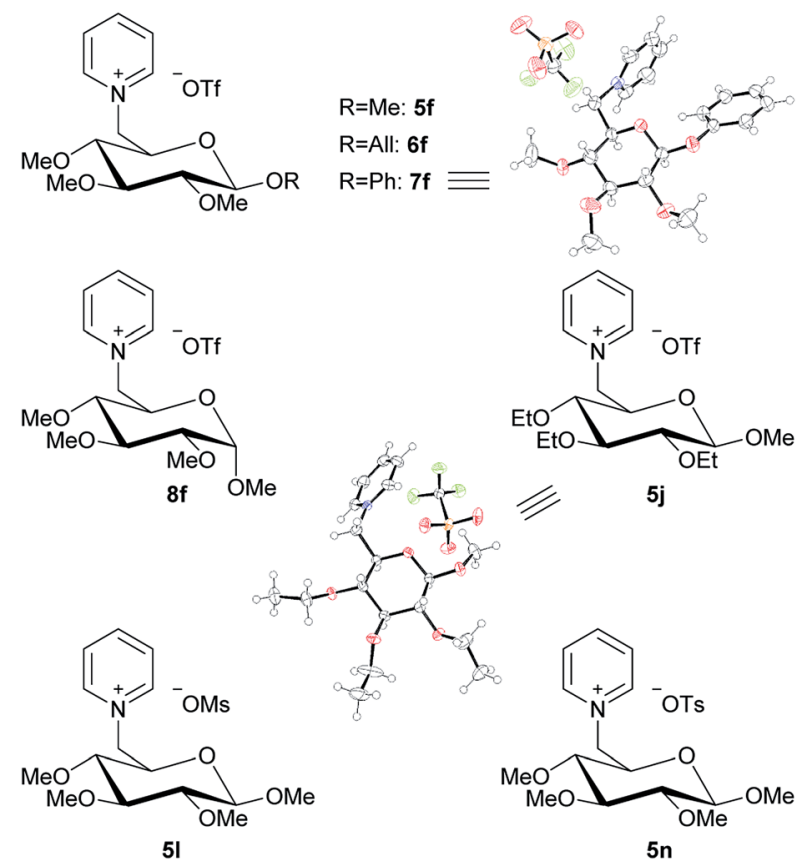

Fig. 7 Overview of glucoside-based pyridinium salts and ORTEPs ${ }^{13}$ of $7 f$ and $5 j$.

\section{Biocompatibility}

For biocompatibility measurements, several commonly known ILs, whose cytotoxicity has already been thoroughly explored, ${ }^{\mathbf{1 4}}$ have been studied in comparison to the new carbohydrate based ILs we synthesized. A few examples of these additionally tested ILs are shown in Fig. 8.

Cell viability assay revealed a strong impact on cell viability at $0.1 \mathrm{~mol} \mathrm{~L}^{-1}$ molar concentration for the predominant share of the evaluated ionic liquids (Fig. 9A-F). According to that only $\left[\mathrm{AlaC}_{1}\right][\mathrm{Lac}]$, choline dihydrogenphosphate and sodium chloride, which was tested for comparison, exhibit no zytotoxic effects. Due to the natural occurrence of these substances in cells, this meets our expectations.

Besides that, further discriminations between the ionic liquids presented herein can be made. Comparison between the different glucose derivatives (Fig. 9A) shows almost no viability for any substance at $c=0.1 \mathrm{~mol} \mathrm{~L}^{-1}$, whereas major differences

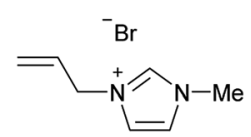

[Amim]Br<smiles>CCC[n+]1ccccc1</smiles>

[CetPyr][Sal]

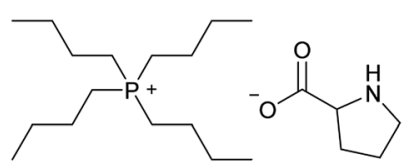

$\left[\mathrm{P}_{4444}\right][\mathrm{Pro}]$<smiles>O=C([O-])c1ccccc1O</smiles><smiles>COC(=O)C[NH3+]</smiles>

$\left[\mathrm{GlyC}_{1}\right] \mathrm{NO}_{3}$
Fig. 8 Examples of additional ILs used in cell viability assay. 

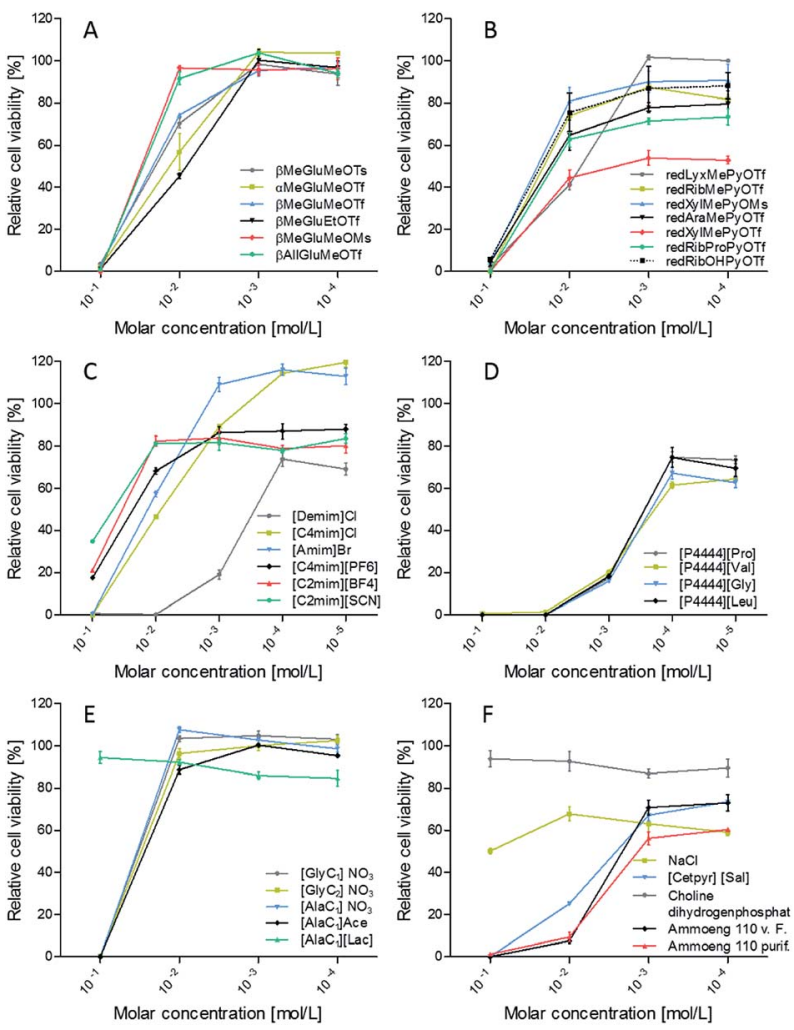

Fig. 9 Relative cell viability of L929 mouse fibroblasts after $48 \mathrm{~h}$ cultivation in a dilution series of the ionic liquids compared to the pure cell culture medium control ( $n=4$, mean \pm SEM). (A) Glucoside based ILs; (B) 1-deoxy-pentose based ILs; (C) imidazolium based ILs; (D) ILs based on tetrabutylphosphonium cation and amino acids as anion; (E) ILs based on amino acids as cation; (F) further natural salts and ILs.

can be found at a concentration of $10^{-2} \mathrm{~mol} \mathrm{~L}^{-1}$. A change of the anomeric form from $\beta$-glucose to $\alpha$-glucose results in a decreased viability.

Moreover, results indicate a major impact of the sort of anion on biocompatibility. For $\beta \mathrm{MeGluMePyr}^{+}$viability rises for following anions in the order: ${ }^{-}$OTs $<{ }^{-}$OTf $<{ }^{-}$OMs. This effect is supported by redXylMePyr ${ }^{+}$with the counterions ${ }^{-}$OTf $<$ - OMs (Fig. 9B). Surprisingly, the substitution of the methyl group by an allylic group at the anomeric center diminishes the cytotoxicity of the triflate anion.

For 1-deoxy-pentoses different viabilities could be observed in the following order: lyxose $\leq$ xylose $<$ arabinose $<$ ribose. Ribose derivatives are naturally found in all nucleotides (DNA, RNA) and hence in all cells, while lyxose can be found in the cell walls of few bacteria and xylose and arabinose in the polysaccharides of plants. Hence, ribose derivatives should be tolerated better by cells with mammalian origin.

Thus, the use of substances with biological origin such as carbohydrates and amino acids is a promising approach for improving the biocompatibility of ionic liquids. To test this, a common tetrabutylphosphonium cation $\left[\mathrm{P}_{4444}\right]$ was countered with four different anions derived from proteinogenic hydrophobic amino acids: proline, valine, glycine and leucine (Fig. 9D). The resulting ionic liquids exhibit cytotoxic effects over the whole concentration range. There are no significant differences between the different anions.

In contrast amino acid derivatives from alanine and glycine as cations exhibit no cytotoxic effects at a concentration of $10^{-2} \mathrm{~mol} \mathrm{~L}^{-1}$ (Fig. 9E). There is also no difference between methoxy- or ethoxy esters in the glycine derivatives. According to the counter ion no significant differences between nitrate and acetate can be found.

Hence, using naturally occurring substances and their derivatives to generate the cation opens up new fields of application, such as biomedical applications. It is worth noting that the IL $\left[\mathrm{AlaC}_{1}\right][\mathrm{Lac}]$ shows good viability already at concentrations of $0.1 \mathrm{~mol} \mathrm{~L}^{-1}$, but compared to the other [AlaC ${ }_{1}$ ] derivatives a slightly worse impact on the biocompatibility at lower concentrations. Further studies have to be performed to shed light on this phenomenon (Tables 1 and 2).

\section{Thermal analysis}

The analysis of the melting points of our 16 new carbohydrate based pyridinium salts allows the categorization into the class of ionic liquids, which are per definition salts with a melting point under $100{ }^{\circ} \mathrm{C}$.

As such, only $\beta$ PhGluMePyrOTf 7f, $\beta$ MeGluEtPyrOTf $5 \mathbf{j}$ and $\beta$ MeGluMePyrOTs 5n do not qualify as ionic liquids, while all other glucoside- and 1-deoxy-pentose products exhibit melting points under $100{ }^{\circ} \mathrm{C}$, with many of them even being room temperature ionic liquids (Tables 3 and 4 ).

While most of the 1-deoxy-pentose based ILs are liquid at room temperature (Table 4) and such don't allow a direct comparison of the impact of configuration and varying groups on the melting point, such comparisons can be made for the glucoside based products (Table 3 ).

The type and configuration of the group at the anomeric center has a high influence on the melting point. A trend of $\beta$ OMe $<\beta$ OAll $\leq \beta$ OPh was found for the glucosides 5-7f. The double bonds of allyl and phenyl groups allow more interactions between the cations than the methyl group, leading to this trend. Furthermore, $\beta$ MeGluMePyrOTf $\mathbf{5 f}$ is liquid at room

Table 1 Relative cell viability of L929 mouse fibroblasts with carbohydrate based ILS

\begin{tabular}{|c|c|c|c|}
\hline No. & Cation & Anion & $\mathrm{EC}_{50}\left[\mathrm{mmol} \mathrm{L}^{-1}\right]$ \\
\hline $1 \mathrm{i}$ & redRibMePyr & OTf & 46.40 \\
\hline $2 \mathbf{i}$ & redLyxMePyr & OTf & 25.19 \\
\hline $3 \mathbf{i}$ & redXylMePyr & OTf & 38.65 \\
\hline $4 \mathbf{i}$ & redAraMePyr & OTf & 40.37 \\
\hline $1 k$ & redRibOHPyr & OTf & 54.80 \\
\hline $1 v$ & redRibPrPyr & OTf & 136.62 \\
\hline $5 f$ & $\beta$ MeGluMePyr & OTf & 41.73 \\
\hline $6 f$ & $\beta$ AllGluMePyr & OTf & 36.40 \\
\hline $7 f$ & $\beta$ PhGluMePyr & OTf & n.m. ${ }^{a}$ \\
\hline $8 f$ & $\alpha$ MeGluMePyr & OTf & 49.88 \\
\hline 51 & $\beta$ MeGluMePyr & OMs & 57.60 \\
\hline $5 n$ & $\beta$ MeGluMePyr & OTs & 51.49 \\
\hline
\end{tabular}

${ }^{a} 7 \mathbf{f}$ was not measured due to its very poor solubility in water. 
Table 2 Relative cell viability of L929 mouse fibroblasts with several $\mathrm{ILS}^{15-18}$

\begin{tabular}{lll}
\hline Cation & Anion & $\mathrm{EC}_{50}\left[\mathrm{mmol} \mathrm{L}^{-1}\right]$ \\
\hline $\mathrm{P}_{4444}$ & $\mathrm{Pro}$ & 0.575 \\
$\mathrm{P}_{4444}$ & Val & 0.775 \\
$\mathrm{P}_{4444}$ & $\mathrm{Gly}$ & 0.875 \\
$\mathrm{P}_{4444}$ & $\mathrm{Leu}$ & 0.725 \\
$\mathrm{GlyC}_{1}$ & $\mathrm{NO}_{3}$ & 35 \\
$\mathrm{GlyC}_{2}$ & $\mathrm{NO}_{3}$ & 20 \\
AlaC $_{1}$ & $\mathrm{NO}_{3}$ & 20 \\
AlaC & $\mathrm{Lac}_{1}$ & 25 \\
Choline $_{\text {Amim }}$ & $\mathrm{H}_{2} \mathrm{PO}_{4}$ & 30 \\
$\mathrm{C}_{2}$ mim & $\mathrm{Br}_{4}$ & 15 \\
$\mathrm{C}_{2}$ mim & $\mathrm{BF}_{4}$ & 4 \\
$\mathrm{C}_{4}$ mim & $\mathrm{SCN}$ & 8 \\
$\mathrm{C}_{4}$ mim & $\mathrm{Cl}$ & 10 \\
$\mathrm{C}_{10}$ mim (demim) & $\mathrm{PF}_{6}$ & 7 \\
Ammoeng $110 ®$ & $\mathrm{Cl}$ & 0.035 \\
Ammoeng $110 \circledR$ purif. & - & 1.07 \\
Cetpyr & - & 3.08 \\
Na & $\mathrm{Sal}$ & 0.038 \\
\end{tabular}

Table 3 Melting points and decomposition points of glucoside based products

\begin{tabular}{lllll}
\hline No. & Cation & Anion & $\mathrm{mp}\left[{ }^{\circ} \mathrm{C}\right]$ & $\mathrm{dp}\left[{ }^{\circ} \mathrm{C}\right]$ \\
\hline $\mathbf{5 f}$ & $\beta$ MeGluMePyr & OTf & Liquid at r.t. & 225 \\
$\mathbf{6 f}$ & $\beta$ AllGluMePyr & OTf & $66-70$ & 205 \\
$\mathbf{7 f}$ & $\beta$ PhGluMePyr & OTf & $164-168$ & 225 \\
$\mathbf{8 f}$ & $\alpha$ MeGluMePyr & OTf & $95-100$ & 242 \\
$\mathbf{5 j}$ & $\beta$ MeGluEtPyr & OTf & $118-120$ & 215 \\
$\mathbf{5 1}$ & $\beta$ MeGluMePyr & OMs & $60-63$ & 250 \\
$\mathbf{5 n}$ & $\beta$ MeGluMePyr & OTs & $135-138$ & 242 \\
\hline
\end{tabular}

Table 4 Melting points, decomposition points and glass transition temperature of 1-deoxy-pentose based products

\begin{tabular}{llllll}
\hline No. & Cation & Anion & $\mathrm{mp}\left[{ }^{\circ} \mathrm{C}\right]$ & $\mathrm{dp}\left[{ }^{\circ} \mathrm{C}\right]$ & $T_{\mathrm{g}}\left[{ }^{\circ} \mathrm{C}\right]$ \\
\hline $\mathbf{1 i}$ & redRibMePyr & OTf & $48-51$ & 345 & -18 \\
$\mathbf{2 i}$ & redLyxMePyr & OTf & Liquid at r.t. & 325 & -41 \\
$\mathbf{3 i}$ & redXylMePyr & OTf & $32-36$ & 345 & -28 \\
$\mathbf{4 i}$ & redAraMePyr & OTf & Liquid at r.t. & 340 & -38 \\
$\mathbf{1 0}$ & redRibEtPyr & OTf & Liquid at r.t. & 316 & -26 \\
$\mathbf{1 s}$ & redRibAllPyr & OTf & Liquid at r.t. & 301 & n.m. \\
$\mathbf{1 v}$ & redRibPrPyr & OTf & Liquid at r.t. & 235 & -27 \\
$\mathbf{1 k}$ & redRibOHPyr & OTf & Liquid at r.t. & 297 & -30 \\
$\mathbf{1 x}$ & redRibIsoPyr & OMs & 92-94 & 296 & n.m. \\
& & & & &
\end{tabular}

temperature, while $\alpha$ MeGluMePyrOTf 8 f has a melting point close to $100{ }^{\circ} \mathrm{C}$, showing that the configuration of the anomeric center alone has a high impact on the melting point. The change of methyl ether groups in $\mathbf{5} \mathbf{f}$ to ethyl ether groups in $\mathbf{5 j}$ also heightens the melting point significantly. Lastly the corresponding anion also has a high influence, showing a clear trend of OTf $<$ OMs $\leq$ OTs.
The decomposition points of the glucoside products vary from 205 to $250{ }^{\circ} \mathrm{C}$, while the 1-deoxy-pentose products have higher values with 297 to $345^{\circ} \mathrm{C}$. In general, these new products have a good thermal stability.

Glass transition temperatures we measured for the 1-deoxypentose based IL's to acquire further information of the influences of configuration and varying groups on physical properties. Here we see a trend of lyxose $2 \mathbf{i}<$ arabinose $4 \mathbf{i}<$ xylose $3 \mathbf{i}<$ ribose 1i. The impact of the varying groups in positions 2 and 3 on the glass transition temperature is small, with the methyl ether product 1i having the highest and the free $\mathrm{OH}$ group product $1 \mathbf{k}$ the lowest $T_{\mathrm{g}}$ in direct comparison.

\section{Methods}

\section{Cell viability assay}

In order to evaluate the biocompatibility of the carbohydratebased ILs cytotoxicity was tested with Cell Viability Assay Kit (BioAssay systems, Hayward, CA, USA).

L929 mouse fibroblasts (CCL-1, ATCC) were cultured in DMEM (PAN BIOTECH, Aidenbach, Germany) with $4.5 \mathrm{mg}$ glucose and $10 \%$ fetal calf serum (FCS), 1\% Penicillin/ Streptomycin and $3.7 \mathrm{~g} \mathrm{~L}^{-1} \mathrm{NaHCO}_{3}$.

For screening tests $2 \times 10^{4}$ L929 mouse fibroblasts were seeded in a 96-well microtiter plate with $200 \mu \mathrm{L}$ culture medium per well and incubated under cell culture conditions $\left(37^{\circ} \mathrm{C}, 5 \%\right.$ $\mathrm{CO}_{2}$ ) for 24 hours.

To proof cell viability CellQuanti-Blue Cell Viability Assay Kit (BioAssay systems, Hayward, CA, USA) was implemented. 10\% CellQuanti-Blue supplement was added to the wells followed by an incubation of another 2 hours under same conditions. The reductive activity of the cells conducts the metabolic turnover from resazurin to the fluorescent resorufin (absorption $544 \mathrm{~nm}$, emission $590 \mathrm{~nm}$ ) which was detected with the Fluostar optima (BMG LABTECH, Ortenberg, Germany).

\section{Thermal analysis}

Melting points were determined with a micro heating stage (Mikroheiztisch BOETIUS, Dresden, Germany).

Decomposition points have been measured via thermogravimetric analysis using a Labsys 1600 TGA-DSC (SETARAM Instrumentation, Caluire, France).

The differential scanning calorimetry using a Pyris 1 DSC (PerkinElmer, Waltham, USA) allowed the analysis of glass transition temperatures.

\section{Conclusion}

In this work we presented a reproducible strategy to synthesize new carbohydrate based pyridinium salts. Said synthetic pathway was successfully applied on 4 different 1-deoxypentoses as well as 4 different glucosides, leading to overall 16 new products with varying configurations and groups.

Thermal analysis shows that 13 of these new carbohydrate based pyridinium salts qualify as ionic liquids per definition, with most of them even being room temperature ionic liquids. 
Further biocompatibility tests have proven that these ionic liquids are suitable for biomedical applications, as they exhibit a much higher viability than common imidazolium or phosphonium based ILs, which have been tested in comparison. A potential application currently under testing is the usage of these new carbohydrate based ionic liquids as additives in coatings for drug-eluting balloons.

\section{Conflicts of interest}

There are no conflicts to declare.

\section{Acknowledgements}

We thank Prof. H. Ohno for providing us the four tetrabutylphosphonium ILs paired with amino acid anions, which we used in the biocompability tests. We also thank Prof. Schick of the University of Rostock for conducting DSC with our samples.This work was supported by the European Union (ESF/14BM-A55-0048/16) as well as by the Federal Ministry of Education and Research (BMBF) project REMEDIS (FKZ:03IS2081).

\section{Notes and references}

1 (a) K. S. Egorova, E. G. Gordeev and V. P. Ananikov, Chem. Rev., 2017, 117, 7132; (b) P. Wasserscheid, T. Welton, Ionic Liquids in Synthesis, Wiley-VCH, Weinberg, 2002.

2 Selected examples: (a) J. Stoimenovski, D. R. Mac Farlane, K. Bica and R. D. Rogers, Pharm. Res., 2010, 27, 521; (b) K. Bica, H. Rodriguez, G. Gurau, O. A. Cojocaru, A. Riisager, R. Fehrmann and R. D. Rogers, Chem. Commun., 2012, 48, 5422; (c) J. L. Shamshina, S. P. Kelley, G. Gurau and R. D. Rogers, Nature, 2015, 528, 188; (d) A. Cojocaru, J. L. Shamshina and R. D. Rogers, Chim. Oggi, 2013, 31, 24; (e) R. Ferraz, L. C. Branco, C. Prudêncio, J. P. Noronha and Ž. Petrovski, ChemMedChem, 2011, 6, 975.

3 N. Adawiyah, M. Moniruzzaman, S. Hawatulaila and M. Goto, MedChemComm, 2016, 7, 1881.

4 D. Jackson, D. Tong and J. Layland, Int. J. Cardiol., 2017, 226, 77.

5 (a) S. Kaule, I. Minrath, F. Stein, U. Kragl, W. Schmidt, K.-P. Schmitz, K. Sternberg and S. Peterson, PLoS One, 2015, 10, e0116080; (b) S. Peterson, S. Kaule, F. Stein, I. Minrath, K.-P. Schmitz, U. Kragl and K. Sternberg, Mater. Sci. Eng. C, 2013, 33, 4244.

6 H. Ohno and K. Fukumoto, Acc. Chem. Res., 2007, 40, 1122.

7 For review articles see $7 \mathbf{a}$ and $7 \mathbf{b}$, for papers of carbohydrate based ILs see 7c-1 and 8-10.(a) A. Marra, C. Chiappe and A. Mele, Chimia, 2011, 65, 76; (b) N. Kaur, A. Singh and
H. K. Chopra, Mini-Rev. Org. Chem., 2018, 15, 208; (c) V. Kumar, C. E. Olsen, S. J. C. Schäffer, V. S. Parmar and S. V. Malhotra, Org. Lett., 2007, 9, 3905; (d) V. Kumar, C. Pei, C. E. Olsen, S. J. C. Schäffer, V. S. Parmar and S. V. Malhotra, Tetrahedron: Asymmetry, 2008, 19, 664; (e) O. N. Van Buu, A. Aupoix, N. D. T. Hong and G. Vo-Thanh, New J. Chem., 2009, 33, 2060; (f) M. D. R. Gomes da Silva, M. Manuela and A. Pereira, Carbohydr. Res., 2011, 346, 197; $(g)$ N. Ferlin, S. Gatard, A. N. Van Nhien, M. Courty and S. Bouquillon, Molecules, 2013, 18, 11512; $(h)$ R. Jayachandra and S. R. Reddy, Trends Carbohydr. Res., 2015, 7, 60; (i) R. Jayachandra, R. Lakshmipathy and S. R. Reddy, J. Mol. Liq., 2016, 219, 1172; (j) R. Jayachandra and S. R. Reddy, RSC Adv., 2016, 6, 39758; (k) R. Jayachandra, S. R. Reddy and Balakrishna, ChemistrySelect, 2016, 1, 2341; (l) R. Yuan, Y.-j. Wang, Y. Fang, W.-h. Ge, W. Lin, M.-q. Li, J.-b. Xu, Y. Wan, Y. Liu and H. Wu, Chem. Eng. J., 2017, 315, 1026.

8 L. Poletti, C. Chiappe, L. Lay, D. Pieraccini, L. Polito and G. Russo, Green Chem., 2007, 9, 337.

9 O. N. Van Buu and G. Vo-Thanh, Lett. Org. Chem., 2007, 4, 158.

10 P. G. J. Plaza, B. A. Bhongade and G. Singh, Synlett, 2008, 2973.

11 For peracetylation of ribose, lyxose, xylose and arabinose see, in this order: (a) L. Li, B. Lin, Z. Yang, L. Zhang and L. Zhang, Tetrahedron Lett., 2008, 49, 4491; (b) B. L. Kam, J.-L. Barascut and J.-L. Imbach, Carbohydr. Res., 1979, 69, 135; (c) S. G. Patching, S. A. Baldwin, A. D. Baldwin, J. D. Young, M. P. Gallagher, P. J. F. Henderson and R. B. Herbert, Org. Biomol. Chem., 2005, 3, 462; (d) Y. Su, J. Xie, Y. Wang, X. Hu and X. Lin, Eur. J. Med. Chem., 2010, 45, 2713.

12 A. Jeffery and V. Nair, Tetrahedron Lett., 1995, 36, 3627.

13 CCDCs 1914143, 1916778 and 1916780 contains ESI crystallographic data for this paper. $\dagger$

14 T. P. T. Pham, C.-W. Cho and Y.-S. Yun, Water Res., 2010, 44, 352.

15 Most of the ionic liquids used in biocompability tests were purchased from commercial sources. All ILs using $\left[\mathrm{P}_{4444}\right]$ cations were a generous gift of Prof. H. Ohno (Tokyo, Japan).

16 Synthesis of [CetPyr][Sal]: K. Bica, C. Rijksen, M. Nieuwenhuyzen and R. D. Rogers, Phys. Chem. Chem. Phys., 2010, 12, 2011.

17 Synthesis of [Amim][Br]: C. Chardin, J. Rouden, S. Livi and J. Baudoux, Green Chem., 2017, 19, 5054.

18 Synthesis of ILs with amino acid ester cation: G.-H. Tao, L. He, N. Sun and Y. Kou, Chem. Commun., 2005, 3562. 